\title{
Pleuropulmonary Blastoma in 12 Years Old Girl: FNAC Diagnosis
}

Samanta $S^{*}$ and Sharma SK

Eko Diagnostic PVT. LTD., 54, Jawaharlal Nehru Road, kolkata, West Bengal 700071, India

*Corresponding author: Swapan Samanta, Eko Diagnostic PVT. LTD., 54, Jawaharlal Nehru Road, kolkata, West Bengal 700071, India, Tel: 919733365004; E-mail: swapansmnt@gmail.com

Rec date: Sep 26, 2014, Acc date: Oct 27, 2014, Pub date:Oct 29, 2014

Copyright: ( 2014 Samanta S, et al. This is an open-access article distributed under the terms of the Creative Commons Attribution License, which permits unrestricted use, distribution, and reproduction in any medium, provided the original author and source are credited.

\section{Short Communication}

Pleuropulmonary blastoma (PPB) is a rare pleura-based pediatric sarcomatous tumor with divergent differentiation. We are presenting the cytological features of $\mathrm{PPB}$, diagnosed by fine-needle aspiration cytology (FNAC) in a 12-year-old girl which is the fifth case reported so far. The diagnosis was confirmed by biopsy from the mass. Therefore, accurate diagnosis may be achieved by FNAC in cases of PPB.

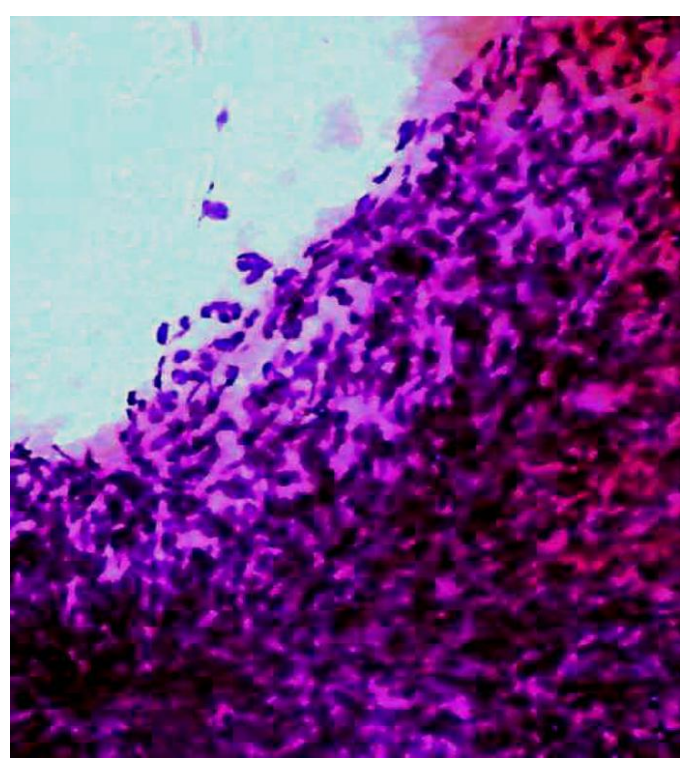

Figure 1: Cellular smears showed pleomorphic spindle tumor cells with irregular nuclear contour, clumped chromatin and indistinct nucleoli (PAP 100X).

A 12 years old girl was suffering from cough, fever and recent illhealth but no hemoptysis for last 3 months. Her imaging study from the thorax revealed a huge solid space occupying lesion involving left lung and also pleura/the chest wall measuring $12 \times 10 \times 8.2 \mathrm{~cm}$. FNAC under CT-guidance was performed and the cellular smears showed pleomorphic spindle tumor cells with irregular nuclear contour, clumped chromatin and indistinct nucleoli (Figures 1 and 2). Focal chondroid material and blastema-like cells were noted. The differential diagnosis suggested by the cytologic findings included rhabdomysosarcoma, teratoma, neuroblastoma, malignant mesenchymoma, pleuropulmonary blastoma, and metastatic tumor. Necrosis was present. No epithelial component or heterologous component was identified. Before surgical removal of the mass a diagnostic confirmation was done by needle biopsy from the mass. The histologic findings were also distinctive, exhibiting diffuse sheets of poorly differentiated pleomorphic spindle cells with coarse chromatin and high mitotic rate.

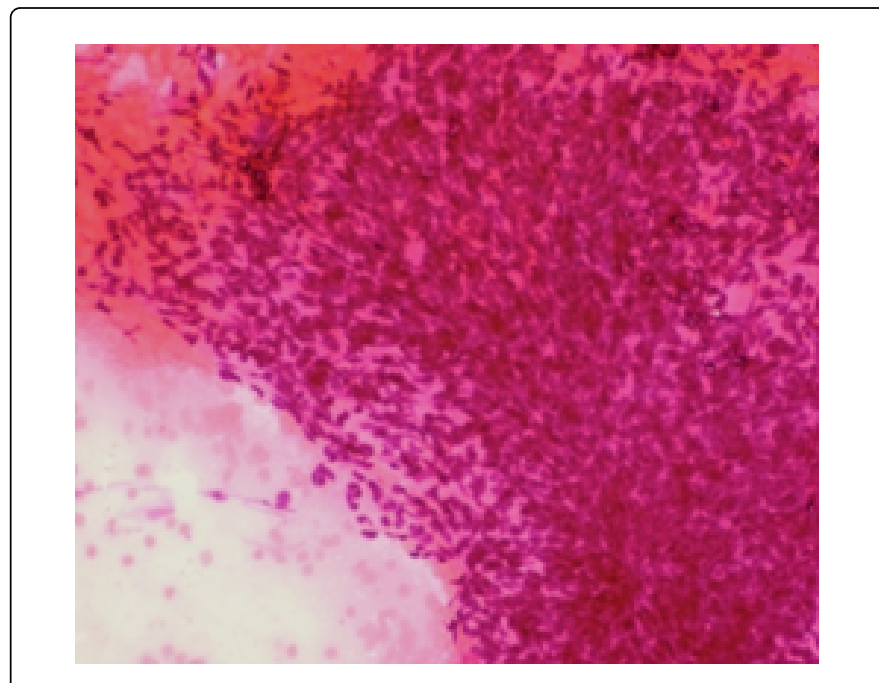

Figure 2: Similar morphology appreciated in PAP-stained smears (PAP 100X).

Till date only four cases of PPB have been reported by cytology so far [1-4]. This neoplasm constitutes a distinct entity which has been reported in the literature as pulmonary blastoma in children. It differs from pulmonary blastoma in adults because of its variable anatomic location, primitive (embryonic-like) blastema and stroma, absence of a carcinomatous component, and potential for sarcomatous differentiation. For histological and anatomic reasons the designation of pleuropulmonaryblastoma is suggested for these intrathoracic neoplasms of childhood rather than pulmonary blastoma.

Therefore, $\mathrm{PPB}$ is a distinct neoplasm which is different from pulmonary blastoma. Secondly, FNAC being a quick and accurate procedure with immediate results should be considered for any mass lesions of the lung or thoracic cavity and might replace diagnostic biopsy and thus avoid hazards of a diagnostic biopsy and related morbidity.

\section{References}

1. Drut R, Pollono D (1998) Pleuropulmonaryblastoma: diagnosis by fineneedle aspiration cytology: a case report. DiagnCytopathol 19: 303-305.

2. Gelven PL, Hopkins MA, Green CA, Harley RA, Wilson MM (1997) Fineneedle aspiration cytology of pleuropulmonaryblastoma: case report and review of the literature. DiagnCytopathol 16: 336-340. 
Citation: Samanta S, Sharma SK (2014) Pleuropulmonary Blastoma in 12 Years Old Girl: FNAC Diagnosis. J Cytol Histol S4: 011. doi: 10.4172/2157-7099.S4-011

Page 2 of 2

3. Nicol KK, Geisinger KR (2000) The cytomorphology pleuropulmonaryblastoma. Arch Pathol Lab Med 124: 416-418.
4. Shin BK, Kim MK, Park SH, Kim CY, Cho SJ, et al. (2001) Fine-needle aspiration cytology of pleuropulmonaryblastoma: a case report with unusual features. DiagnCytopathol 25: 397-402. 